\title{
SEAT BELT FRACTURES OF THE CERVICAL SPINE*
}

\author{
T. K. F. Taylor, Sydney Nade and J. H. Bannister, Sydney, Australia \\ From the Department of Orthopaedics and Traumatic Surgery, The Royal North Shore Hospital of Sydney, \\ St Leonards, New South Wales, and The University of Sydney
}

\begin{abstract}
Three unusual injuries of the cervical spine in wearers of safety belts are reported. In each case, the presence of diagonal bruising and abrasions in the line of the sash strap indicated its involvement in the mechanism of the injury.
\end{abstract}

The role of seat belts in reducing injuries and deaths from motor vehicle accidents has been decisively established in many countries. Since the early report of Garrett and Braunstein (1962), who found little evidence for the existence of a seat belt syndrome, there has been a steady stream of publications on injuries attributable to seat belts. Moreover, there has been a distinct change in the pattern of seat belt injuries with modifications of belt design (Williams and Kirkpatrick 1971). As pointed out by these authors, injury to almost every viscus has now been recorded.

With the lap belts, intra-abdominal injuries were prominent, as were fractures of the upper lumbar spine, most often Chance fractures or variants of these injuries. The mechanism of these injuries was clearly documented by Smith and Kaufer (1969). The diagonal two-point safety strap tended to produce injuries to the thoracic cage, and the pattern varied according to whether the wearer slid under the strap or was thrown against it on impact. In the former event cervical spine injuries could occur. Saldeen (1967) reported three fatal neck injuries, two with decapitation, when wearers of diagonal seat belts were thrown from their cars, their chins apparently catching on the belt. The risk of ejection, with a much higher morbidity and mortality, is all but removed by an effective three-point lap sash belt. This restraint, now made compulsory by legislation in Australia, has strikingly reduced the number of serious intra-abdominal injuries. Williams and Kirkpatrick (1971) studied the reports of sixty-three accident victims who were wearing three-point seat belts. Single rib fractures were the most common injuries, occurring in twenty persons, with multiple fractures in a further eight. As might be suspected, the sternum and clavicle figured prominently, with four and five fractures respectively. Abrasions and contusions of the shoulder and neck were present in eight patients and of the chest in eleven. Injuries of the cervical spine were not recorded. Dehner (1971) commented that the

three-point belt might produce flexion injuries of the neck. The single report we have found of cervical spinal fractures attributable to the combination belt is that by Hamilton (1968), who described two cases, one with a two level injury at the atlanto-axial joint and at C.6-7, and a compression fracture at the cervico-thoracic junction discovered incidentally by radiography. He predicted that the lap sash belt might increase neck injuries.

This paper reports three unusual cervical spine injuries, seen in a four-year period, two of which were sustained by wearers of three-point lap sash belts and one by a two-point diagonal sash belt.

\section{CASE REPORTS}

Case 1-A man aged twenty-nine was involved in a severe road accident, in which he was the driver of one vehicle. Exact details of the crash are not known, but he was wearing a lap sash safety belt, and he was not ejected from the car. Examination on admission to hospital the same day revealed a profound tetraparesis, with features of a Brown-Séquard syndrome, motor impairment being more marked on the right side.

Abrasions were present on the right side of the neck opposite the midcervical region, extending obliquely across the anterior chest; another small one was noted under the chin just to the right of the midline (Fig. 1). The head was noticeably offset to the left on the trunk. There were no other injuries.

Radiographs showed antero-lateral subluxation of the fifth cervical vertebra on the sixth, with crushing of the lateral mass on both sides and considerable lateral displacement (Fig. 2).

Skull traction ( 5 kilograms) was applied but the lateral displacement was unaltered. Anterior spinal fusion from C.5 to C.6 was performed three weeks after injury, in accordance with our usual practice with incomplete cervical cord injuries. The graft incorporated rapidly and the patient was mobilised gradually in a soft collar seven weeks after operation. Steady neurological improvement occurred and has continued in the eighteen months since operation. The patient is now independent and capable of employment not involving heavy manual labour. The displacement of his head to the left remains noticeable.

* Based on a paper presented to the 34th Annual General Meeting of the Australian Orthopaedic Association, Townsville, Queensland, in July 1974.

Professor T. K. F. Taylor, D.Phil.(Oxon.), F.R.C.S., F.R.C.S.(Ed.), F.R.A.C.S Dr Sydney Nade, M.D., F.R.C.S., M.R.C.P.(U.K.)

Dr J. H. Bannister, F.R.C.S.
Department of Orthopaedics and Traumatic Surgery, Royal North Shore Hospital, St Leonards, N.S.W. 2065, Australia. 
Comment-The degree of lateral displacement in this injury is most unusual. This, coupled with the abrasions on the right side of the neck, indicts the sash belt. It is impossible to be precise about the exact mechanism of the injury. The evidence suggests that in the impact,

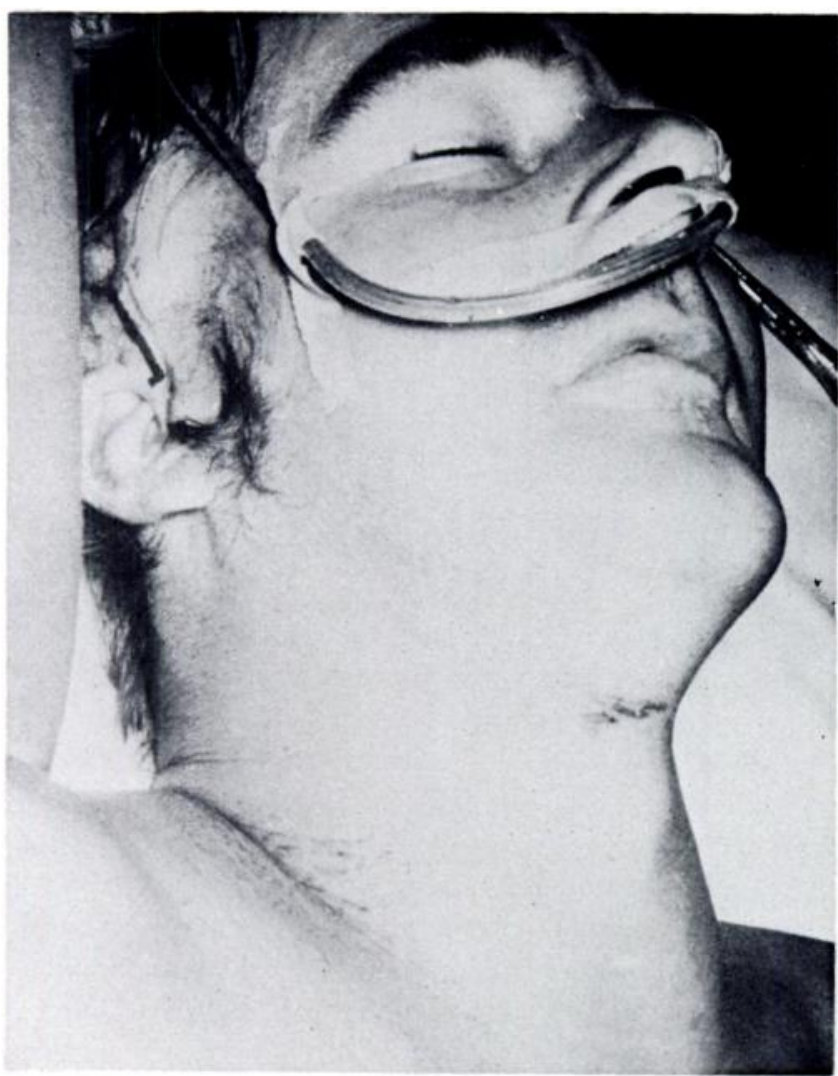

FiG. 1

Case 1-Photograph of the neck made shortly after admission. The bruising under the chin and more laterally is shown.

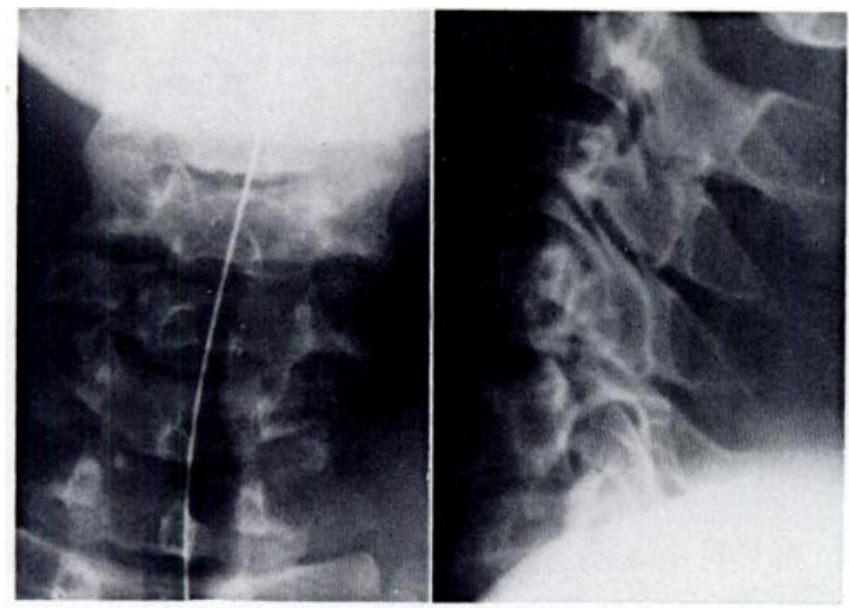

FiG. 2

Case 1-Antero-posterior and lateral radiographs of the cervical spine demonstrating the C.5-6 antero-lateral subluxation.

either the patient was thrown to the right against the sash strap; or an intrusion of the right side of the vehicle into the occupant space, with the sash strap in place, could have forced the upper cervical spine to the left with the trunk restrained by the lap component or other factors. It is presumed that locking of small fracture fragments in the crushed lateral masses prevented realignment.

Case 2-A girl aged seventeen presented with intense neck pain after a road accident in which she had been a rear seat

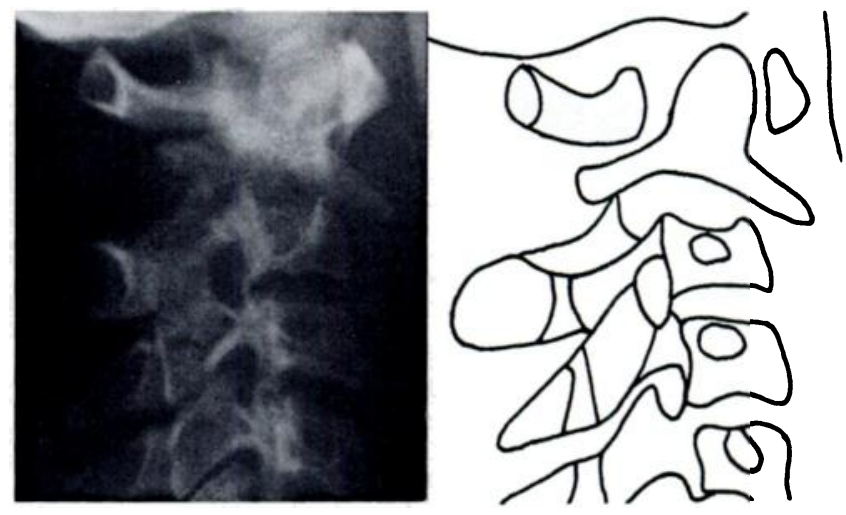

Fig. 3

Case 2-Lateral radiograph of the cervical spine in which the markedly rotated proximal fragment of the dens is seen together with a wide retropharyngeal shadow. A tracing of the fracture outline is shown on the right.

passenger wearing a lap sash safety belt. She had not been thrown from the car. She could not recall the mechanism of injury, but at impact she had been aware of the sudden onset of neck pain.

There was marked limitation of all neck movements, the head being held rigidly to the left by muscle spasm. Severe diagonal bruising and abrasions were present on the left side of the neck, consistent with impingement against the sash strap. In addition, there were multiple small lacerations on the face, trunk and limbs. No other injuries were sustained. Detailed neurological examination revealed no abnormality.

A lateral radiograph showed a fracture through the upper part of the body of the axis with marked rotary displacement (Fig. 3). The outline of the dens and the adjoining parts of the lateral masses, including the upper articular surfaces, was comparable to that seen in a normal trans-oral view. Marked retropharyngeal swelling was noted (Fig. 3). In this instance the trans-oral view could not be interpreted with precision.

The general alignment of the cervical spine from the atlas down was considered satisfactory. The patient was put in a halo plaster with prompt relief of pain. Attempts to centre the head over the trunk caused severe pain; so the position was accepted. Serial radiographs showed no change in position of the fracture. Three weeks after injury a Minerva jacket was applied to allow transfer to a country town. No instability was demonstrable three months after injury and the fracture had healed. Neck movements were regained rapidly. When last seen ten months after injury the patient had no pain, and there was a loss of about one-third of the normal range of movement. Her head remained slightly displaced to the left.

Comment-In this unusual injury the patient was fortunate to have escaped spinal cord injury or death. As yet, the development of an experimental model for the production of fractures of the dens has eluded investigators: it is difficult even to speculate what occurred in our patient. Whatever the mechanism, it is concluded that the sash belt impinging against the neck was a significant contributory factor, as indicated by the severe diagonal soft-tissue injury. 
Case 3-A woman aged twenty-five was the driver of a car which crashed head-on into a telegraph pole. Her front seat passenger died. As in the previous two cases, the exact mechanism of injury is unknown, but the patient recalled the instantaneous onset of neck pain at the moment of impact. On admission to hospital she complained of severe neck pain with occipital radiation. A marked diagonal abrasion with bruising was present on the right side of the neck. Neurological examination was normal.

A lateral radiograph of the cervical spine showed a displaced "hangman's fracture" of the axis with a clear defect in the pedicles. The inferior facets of the axis were dislocated forward on those of the vertebra below (Fig. 4). Skull traction was applied. It was maintained for eight days but there was no change in the fracture-dislocation. The patient was then transferred to our care and a halo plaster was applied. Open reduction was performed two weeks after injury. After removal of the lips of the superior articular processes of C.3, gentle extension reduced the dislocation and the pedicle fractures. A wire was then passed under the arch of the atlas and around the base of the spinous process of the axis to C.3. After decortication, strips of cancellous iliac bone were laid on the posterior elements (Fig. 5).

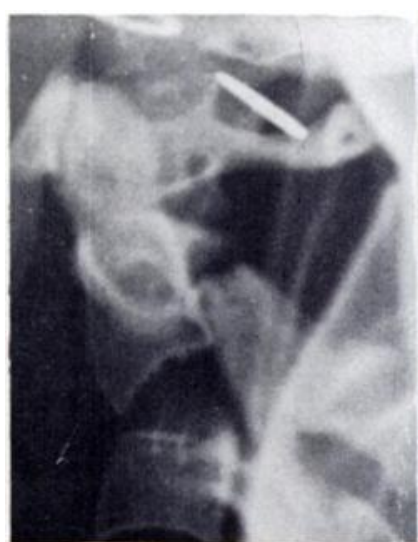

Fig. 4

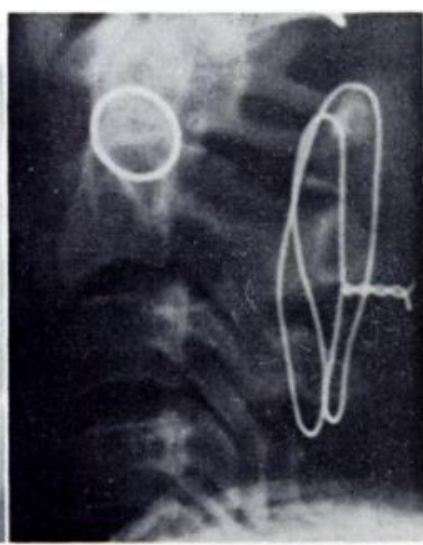

Fig. 5
Case 3. Figure 4-Lateral radiograph showing a "hangman's fracture" with a wide pedicle defect. The overriding of the inferior facets of the axis is shown. Figure 5-Radiograph taken before removal of halo plaster. The alignment is satisfactory and the graft is being incorporated.

The post-operative course was uneventful apart from a transient episode of acute parotitis. After seven weeks the graft was incorporating well and she was mobilised wearing a soft collar. Shortly afterwards she moved to a distant part of the country. Solid fusion occurred and, so far as we know, the patient has not had any further trouble with the neck.

Comment - This injury is a previously undescribed variant of a "hangman's fracture". The pedicle fractures prevented traction from having any significant effect on the facet dislocation. The pattern of the spinal injury and the neck abrasion suggest that the responsible flexion force was enhanced in some way by sash belt fixation at the mid-cervical region.

\section{DISCUSSION}

The mechanisms of most spinal fractures are now fairly well understood (Nicoll 1949; Smith and Kaufer 1969;
Holdsworth 1970). It follows that unusual fractures result from unusual mechanisms, and this is what happened in our patients. Here, a common factor was sash strap impingement against the soft tissues of the neck, and this in some way influenced the mechanism of the injury. Possible explanations are given in the comment on each case. The ability of a sash strap to produce cervical trauma would be enhanced if it were coiled into a narrower band, such as tends to happen if the strap is incorrectly adjusted. Our patients could not recall the manner in which their seat belts were worn.

The Australian design rules for seat belts specify that the sash component be anchored to the pillar between doors in a conventional four-door sedan. There was considerable allowance for the point of attachment, but in the light of information from crash investigations the design rules have been modified to indicate specific areas in which the anchorages should be placed. Australianbuilt vehicles must now conform to strict specifications laid down in these rules (Henderson 1975). Herbert and Leitis (1973), in a study on sash discomfort in seat belt wearers, found that when the anchorage was too high the strap pressed against the wearer's neck; when too low, it tended to fall off the shoulder. A number of popular cars were found to be quite deficient in these respects. These workers developed a sash guide to improve effectiveness and wearer comfort when structural limitations in vehicles precluded optimal siting of the sash attachment. Such a guide might well find wide application considering variation in body habitus.

The compulsory wearing of three-point seat belts in Australia has provided an opportunity for study of their effectiveness in reducing morbidity and mortality in road traffic accidents. Henderson and Wood (1973) reported a statistically significant 25 per cent drop in the number of predicted vehicle occupant deaths for New South Wales in 1972, the year after legislation was introduced. In Victoria, an adjoining state, there has been a decrease in the number of spinal cord injuries from motor vehicle accidents since compulsory wearing of seat belts. There has also been a fall in the ratio of paraplegics to tetraplegics, together with an overall decrease in the severity of cord damage (Burke 1973). Burke mentioned one patient with severe cervical spondylosis who was tetraplegic from a C.6-7 subluxation. One can imagine that simple cervical sprains might well be increased in head-on and rear end collisions if the trunk were effectively held by the sash belt. So far no information on this is available. Head injuries are now the major cause of death in seat belt wearers in this country, as shown by Henderson and Wyllie (1973), who studied necropsy findings in fortyeight fatally injured persons. Neck injuries were noted only once; but even major cervical spine injuries might escape detection unless specifically sought at necropsy. The association between head injuries and cervical spinal fractures is well known.

Henderson and Wyllie also pointed out that even 
though significant progress has been made in the protection of motor vehicle occupants there was still room for improvement in seat belt geometry, installation, dynamic performance and automatic adjustability. The principal objective of the seat belt is to disperse deceleration forces with maximum safety to the wearer, who is by no means immune to injury. Research development of the "air bag" may provide an additional worthwhile safety device. Mandatory installation and wearing of seat belts is one thing, but correct wearing is another. Public education is needed and particularly so for the casual passenger. Twelve of the forty-eight cases studied by Henderson and Wyllie were in passengers.

The potential of the sash strap to cause cervical spinal injuries warrants further investigation including routine detailed examination of the proximal vertebral column in fatally injured wearers. Just as abdominal bruising from a lap belt was highly suggestive of intraabdominal injury, we suggest that diagonal neck bruising should arouse suspicions of cervical spinal trauma.

\section{ADDENDUM}

We have recently treated yet another patient with a fracture of the body of the axis (similar to Case 2 but with less displacement) who was the driver of a car which rolled over. She had a very obvious burn on the right side of the neck and bruising over the right breast and across the abdomen which were directly in the line of the sash and lap components respectively of her seat belt.

We wish to thank Mr K. I. Clifford of the Department of Illustration, the University of Sydney, for preparation of the illustrations, and Ms S. Tandy-Cockram for typing the manuscript.

\section{REFERENCES}

Burke, D. C. (1973) Spinal cord injuries and seat belts. The Medical Journal of Australia, 2, 801-806.

Dehner, J. R. (1971) Seat belt injuries of the spine and abdomen. American Journal of Roentgenology, Radium Therapy and Nuclear Medicine, $111,833-843$.

Garrett, J. W., and Braunstein, P. W. (1962) The seat belt syndrome. Journal of Trauma, 2, 220-238.

Hamilton, J. B. (1968) Seat belt injuries. British Medical Journal, 4, 485-486.

Henderson, M. (1975) Personal communication.

Henderson, M., and Wood, R. (1973) Compulsory wearing of seat belts in New South Wales, Australia. An evaluation of its effect on vehicle occupant deaths in the first year. The Medical Journal of Australia, 2, 797-801.

Henderson, M., and Wyllie, J. M. (1973) Seat belts-limits of protection: A study of fatal injuries among seat belt wearers. Proceedings of the 17th Stapp Car Crash Conference, Oklahoma, December 12-17, 1973, pp. 35-66. New York: Society of Automotive Engineers, Inc.

Herbert, D. C., and Lettis, V. (1973) Sash discomfort in seat belts. Research Paper, Traffic Accident Research Unit, Department of Motor Transport, New South Wales.

Holdsworth, Sir F. (1970) Fractures, dislocations, and fracture-dislocations of the spine. Journal of Bone and Joint Surgery, 52-A, 15341551.

Nicoll, E. A. (1949) Fractures of the dorso-lumbar spine. Journal of Bone and Joint Surgery, 31-B, 376-394.

Saldeen, T. (1967) Fatal neck injuries caused by use of diagonal safety belts. Journal of Trauma, 7, 856-862.

Smith, W. S., and Kaufer, H. (1969) Patterns and mechanisms of lumbar injuries associated with lap seat belts. Journal of Bone and Joint Surgery, 51-A, 239-254.

Williams, J. S., and Kirkpatrick, J. R. (1971) The nature of seat belt injuries. Journal of Trauma, 11, 207-218. 